\title{
pH-Independent Heat Capacity Changes during Phosphorolysis Catalyzed by the Pyrimidine Nucleoside Phosphorylase from Geobacillus thermoglucosidasius
}

\author{
Felix Kaspar, ${ }^{1,2 *}$ Darian S. Wolff, ${ }^{1}$ Peter Neubauer, ${ }^{1}$ Anke Kurreck, ${ }^{1,2}$ Vickery L. Arcus ${ }^{3}$ \\ ${ }^{1}$ Chair of Bioprocess Engineering, Institute of Biotechnology, Faculty III Process Sciences, Technische \\ Universität Berlin, Straße des 17. Juni 135, D-10623, Berlin, Germany. \\ ${ }^{2}$ BioNukleo GmbH, Ackerstraße 76, D-13355 Berlin, Germany. \\ ${ }^{3}$ Te Aka Mātuatua - School of Science, Te Whare Wānanga o Waikato - University of Waikato, \\ Hamilton 3240, New Zealand.
}

Enzyme-catalyzed reactions sometimes display curvature in their Eyring plots in the absence of denaturation, indicative of a change in activation heat capacity. However, $\mathrm{pH}$ and (de)protonation effects on this phenomenon have remained unexplored. Herein, we report a kinetic characterization of the thermophilic pyrimidine nucleoside phosphorylase from Geobacillus thermoglucosidasius across a two-dimensional working space covering $35^{\circ} \mathrm{C}$ and $3 \mathrm{pH}$ units with two substrates displaying different $\mathrm{pK}_{\mathrm{a}}$ values. Our analysis revealed the presence of a measurable activation heat capacity change $\Delta C_{p}^{\ddagger}$ in this reaction system, which showed no significant dependence on medium $\mathrm{pH}$
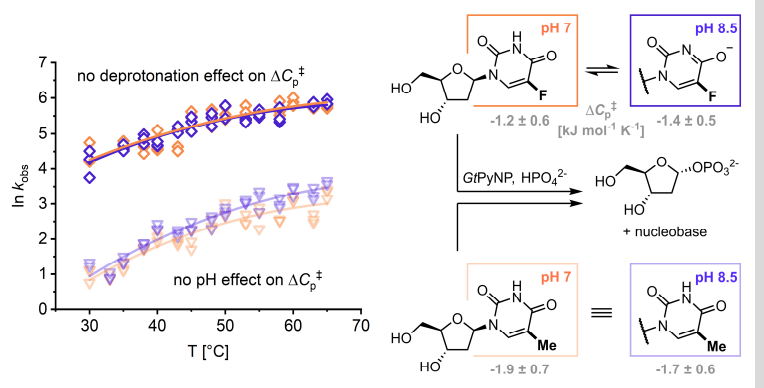
or substrate charge. Our results further describe the remarkable effects of a single halide substitution which has a minor influence on $\Delta C_{p}^{\ddagger}$ but conveys a significant kinetic effect by lowering the activation enthalpy, causing a $>10$-fold rate increase. Collectively, our results present an important piece in the understanding of enzymatic systems across multidimensional working spaces where the choice of reaction conditions can affect rate, affinity and thermodynamic phenomena independently of one another.

Temperature is a central variable for the rates of chemical reactions. Most first-order reactions follow an exponential rate-temperature relationship as described by the Eyring equation. ${ }^{[1,2]}$

$$
k=\frac{k_{b} T \kappa}{h} \exp \left(\frac{-\Delta H^{\ddagger}+T \Delta S^{\ddagger}}{R T}\right)
$$

Herein, $k$ is the rate constant, $T$ is the reaction temperature, $R$ is the universal gas constant and $k_{b}$ and $h$ are the Boltzmann and Planck constants, respectively. $\Delta H^{\ddagger}$ and $\Delta S^{\ddagger}$ are the enthalpy and entropy change between the reactants and the transition state. The transmission coefficient $\kappa$ is presumed to be 1 hereafter. Despite this equation holding remarkably well for most chemical transformations, there is a growing consensus that enzyme-catalyzed reactions can deviate from the rate-temperature relationship predicted by the Eyring equation by displaying a curvature in their Eyring plots. $^{[3,4]}$ This behavior has been shown to originate from a heat capacity change between the enzyme substrate complex and the enzyme transition state complex, caused by preorganization of the enzyme along the reaction coordinate (i.e. during transition state binding). ${ }^{[5-14]}$ This molecular property has been described by the Macromolecular Rate Theory (MMRT), which extends the Eyring equation by terms accounting for activation heat capacity changes. ${ }^{[5]}$

$$
\begin{aligned}
k=\frac{k_{b} T}{h} \exp \left[\frac{-\Delta H_{T 0}^{\ddagger}-\Delta C_{p}^{\ddagger}\left(T-T_{0}\right)}{R T}\right. & \\
& \left.+\frac{\Delta \mathrm{S}_{T 0}^{\ddagger}+\Delta C_{p}^{\ddagger}\left(\ln T-\ln T_{0}\right)}{R}\right]
\end{aligned}
$$

Here, $\Delta C_{p}^{\ddagger}$ is the change in activation heat capacity and $\Delta H_{T 0}^{\ddagger}$ and $\Delta \mathrm{S}_{T 0}^{\ddagger}$ are the activation enthalpy and entropy, respectively, at an arbitrary reference temperature $T_{0}$. Thus, MMRT provides a molecular explanation for the observed curvature in Eyring plots in the absence of denaturation, which has been demonstrated for a variety of biocatalytic reactions (see Table S1 for a list). Nonetheless, previous characterizations of rate-temperature relationships of various enzymes via Eyring plots have generally been performed at only one $\mathrm{pH}$ value (typically $\mathrm{pH} 7$ in phosphate buffer, Table S1), leaving the $\mathrm{pH}$ dimension of the reaction space, as well as protonation effects on any of the activation parameters in equations (1) and (2), largely unexplored.

In this context we became interested in the ratetemperature relationships of thermostable nucleoside phosphorylases $(\mathrm{NPs})^{[15]}$ as these enzymes allow an experimental coverage of both a broad $\mathrm{pH}$ and temperature window. NPs perform the reversible phosphorolysis of nucleosides (Figure 1A) and are key catabolic enzymes in all kingdoms of life. ${ }^{[16]}$ Owing to their important role in various diseases, ${ }^{[17-22]}$ their catalytic properties have received considerable attention. Furthermore, NPs are used in synthetic chemistry for the preparation of pentose-1phosphates and nucleoside analogs ${ }^{[23-28]}$ and have been employed as analytical tools. ${ }^{[29]}$ While purine NPs have been researched intensively, ${ }^{[30-36]}$ including their ratetemperature relationships, ${ }^{[10,37]}$ comparably little is known about rate-temperature relationships of reactions catalyzed by the structurally distinct pyrimidine NPs. ${ }^{[38]}$ Since these enzymes typically operate across a wide $\mathrm{pH}$ window with similar rate constants ${ }^{[39,40]}$ and convert electronically diverse substrates, ${ }^{[38,39]}$ we hypothesized that they would present a convenient model system to interrogate $\mathrm{pH}$ and deprotonation effects on the Eyring plots of nucleoside phosphorolysis, as an example of a simple nucleophilic 
substitution. Thus, we questioned if there exists an activation heat capacity change during the phosphorolysis reactions catalyzed by thermostable pyrimidine NPs and, if so, whether this effect shows any $\mathrm{pH}$ - and/or protonationdependence across the broad working space of these enzymes. Herein, we report a kinetic characterization of the thermophilic pyrimidine NP from Geobacillus thermoglucosidasius (GtPyNP) across a two-dimensional working space covering $35^{\circ} \mathrm{C}$ and $3 \mathrm{pH}$ units with two substrates displaying different $\mathrm{pK}_{\mathrm{a}}$ values (thymidine, 1a, $\mathrm{pK}_{\mathrm{a}} \approx 10.0$ and 2'-deoxy-5-fluorouridine, $\mathbf{1 b}, \mathrm{pK}_{\mathrm{a}} \approx 7.3$, ${ }^{[41]}$ Figure 1A).

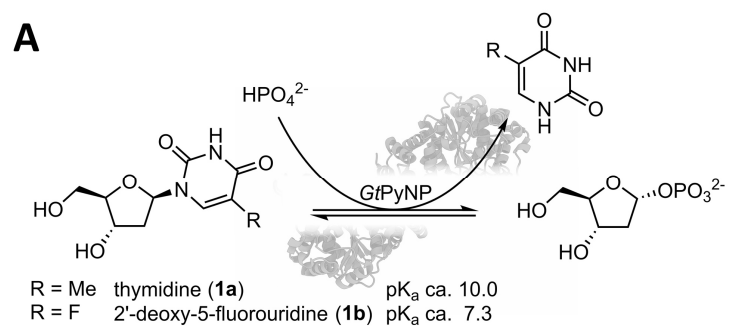

B

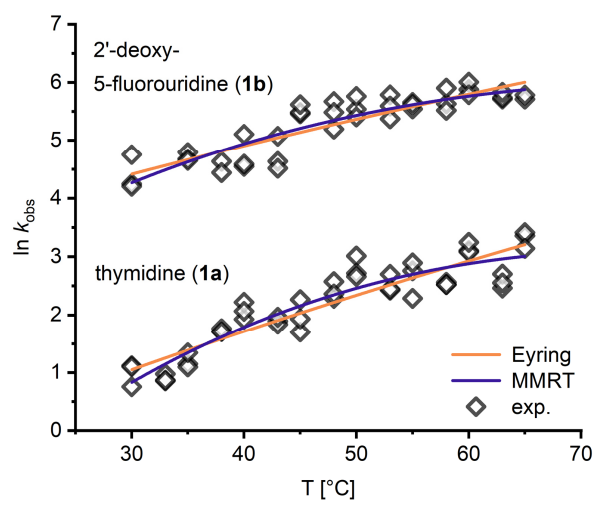

Figure 1. Phosphorolysis of the nucleosides $\mathbf{1 a}$ and $\mathbf{1 b}$ catalyzed by GtPyNP (A) and its rate-temperature relationship at $\mathrm{pH} 7(\mathbf{B})$. Both $\mathrm{pK}_{\mathrm{a}}$ values listed in $\mathbf{A}$ represent approximate values at $25^{\circ} \mathrm{C}$ and are subject to slight changes at higher temperatures. Data in $\mathbf{B}$ were acquired via sampling and discontinuous monitoring of reactions with a high-throughput assay ${ }^{[42,43]}$ and fitted to the Eyring (1) and MMRT (2) equations, as described in the Supplementary Information. Please see the externally hosted Supporting Information for raw data and calculations. ${ }^{[44]}$

First, we assayed GtPyNP for phosphorolytic conversion of $\mathbf{1 a}$ and $\mathbf{1 b}$ at $\mathrm{pH} \mathrm{7,} \mathrm{employing} \mathrm{deconvolution} \mathrm{of} \mathrm{UV}$ absorption spectra for reaction monitoring. ${ }^{[42,43]}$ To this end, several preliminary experiments were essential, as we aimed to acquire activity data unaffected by denaturation effects $\left(T_{\mathrm{M}}=77.5^{\circ} \mathrm{C}\right.$, Figure $\left.\mathrm{S} 1\right)$, which required the selection of experimental conditions enabling sufficient stability of the enzyme (please see the Supplementary Information for details). Employing saturating substrate concentrations and a temperature window of $30-65{ }^{\circ} \mathrm{C}$, the methylated nucleoside 1a was converted with observed rate constants $k_{\text {obs }}$ of 2.1-30.3 s $\mathrm{s}^{-1}$, showing a clear temperaturedependence (Figure 1B). Both the Eyring and the MMRT equation provided reasonably good fits of the experimental data $\left(\mathrm{R}^{2}=0.84\right.$ and 0.86$)$. However, the Eyring fit showed a systematic deviation from the data by overestimating at the extremes of the temperature and underestimating in the middle of the dataset, while also suggesting a considerable enthalpy-entropy trade-off $\left(\Delta H^{\ddagger}=49.9 \mathrm{~kJ} \mathrm{~mol}^{-1}\right.$ and $\Delta S^{\ddagger}=-71.8 \mathrm{~J} \mathrm{~mol}^{-1} \mathrm{~K}^{-1}$ ). In contrast, the MMRT fit provided a more realistic description of the dataset by reflecting the experimental data more evenly throughout the full temperature range, as supported by the Akaike information criterion (AIC, Table S3). ${ }^{[45]}$ This fit yielded a heat capacity change $\Delta C_{p}^{\ddagger}$ of $-1.9 \pm 0.7 \mathrm{~kJ} \mathrm{~mol}^{-1} \mathrm{~K}^{-1}$, manifesting itself in a moderate but significant curvature in the graph. A similar observation was made for the fluorinated nucleoside $\mathbf{1 b}$, whose phosphorolysis showed a $\Delta C_{p}^{\ddagger}$ of $-1.2 \pm 0.6 \mathrm{~kJ} \mathrm{~mol}^{-1} \mathrm{~K}^{-1}$. This suggests a comparable binding of the transition states of both substrates, which is likely rooted in the nearly equal steric demand of these substrates as well as their identical electronic interactions with the H-bonding residues in the GtPyNP active site under these conditions. In contrast to $\mathbf{1 a}$, the fluorinated $\mathbf{1 b}$ was converted with much higher rate constants of 69.7-406.6 s-1. Interestingly, this increase of $k_{o b s}$ originated from a significantly lower activation enthalpy $\left(\Delta H_{298 K}^{\ddagger}=\right.$ $92.2 \mathrm{~kJ} \mathrm{~mol}^{-1}$ for $\mathbf{1 a}$ and $62.5 \mathrm{~kJ} \mathrm{~mol}^{-1}$ for $\left.\mathbf{1 b}\right)$, which outweighed the lower entropic contribution (Table S3) and most likely reflects a weaker glycosidic bond caused by electron withdrawal through the fluorine substituent. In line with the lower activation enthalpy observed for $\mathbf{1 b}$, its phosphorolysis showed a shallower temperaturedependence, reflected by a rate increase of factor 4.9 between 30 and $65^{\circ} \mathrm{C}$, compared to a factor of 8.6 for $\mathbf{1 a}$.

Collectively, these results provide several insights. First, despite disagreeing literature, ${ }^{[46]}$ this untangling of activity and denaturation effects revealed that GtPyNP possesses no classical optimum temperature. ${ }^{[5]}$ Previous assignments of an optimum temperature of this enzyme ${ }^{[46]}$ can likely be ascribed to enzyme denaturation since its theoretical optimum temperature is approximately equal to its melting temperature $\left(T_{\mathrm{M}}=77.5^{\circ} \mathrm{C}\right.$, theoretical $T_{\text {opt }}=75^{\circ} \mathrm{C}$ for $\mathbf{1 a}$ or $79^{\circ} \mathrm{C}$ for $\mathbf{1 b}$, Figures S1 and S6). Secondly, the data presented above lend further evidence to the notion that binding of the substrate and binding of the transition state are unrelated phenomena, ${ }^{[47]}$ as enzymes primarily discriminate between substrates on the transition state level rather than via selective binding of the ground states of substrates. This is evident here in the observed difference of the affinities for the two substrates $\left(K_{\mathrm{M}}=0.6 \mathrm{mM}\right.$ for $1 \mathrm{a}$ and $3.1 \mathrm{mM}$ for $\mathbf{1 b})$ and the similarity of $\Delta C_{p}^{\ddagger} \quad(-1.9$ and $\left.-1.2 \mathrm{~kJ} \mathrm{~mol}^{-1} \mathrm{~K}^{-1}\right)$. Thirdly, considering previous work indicating that the overall phosphorolysis of $\mathbf{1 a}$ and $\mathbf{1 b}$ proceeds with almost the same equilibrium state thermodynamics, ${ }^{[39]}$ these results indicate that electron withdrawal by the fluorine substituent primarily has a kinetic effect in this reaction system and almost no thermodynamic one. This is reflected by the lower $\Delta H^{\ddagger}$ for 1b compared to 1a contrasting their almost identical equilibrium constants $\left(K_{\text {eq }}=0.15\right.$ for $\mathbf{1 a}$ and 0.12 for $\left.\mathbf{1 b}\right)$ and apparent net thermodynamic parameters $\Delta H$ and $\Delta S$ (Scheme S2). ${ }^{[39]}$ 
Next, we extended this kinetic characterization to the entire $\mathrm{pH}$ range accessible with GtPyNP to examine the impact of reaction $\mathrm{pH}$ and substrate deprotonation on the kinetic behavior of this system. We hypothesized that the medium $\mathrm{pH}$ might influence the surface charge of the protein and, consequently, its molecular dynamics, which might be reflected by the heat capacity changes during catalysis. Furthermore, $\mathbf{1 b}\left(\mathrm{pK}_{\mathrm{a}} \approx 7.3\right)^{[41]}$ becomes fully deprotonated at higher $\mathrm{pH}$ values and we expected to see $\mathrm{pH}$ effects on its activation thermodynamics. To probe these hypotheses, we obtained Eyring plots for the phosphorolysis of $\mathbf{1 a}$ and $\mathbf{1 b}$ from $\mathrm{pH} 7-10$ in steps of $0.5 \mathrm{pH}$ units (Figure S4). In all but one condition, the AIC supported the MMRT model (2) as the better fit, substantiating the presence of a negative $\Delta C_{p}^{\ddagger}$ (Table S3, Figure 2). Unexpectedly, the reaction $\mathrm{pH}$ generally had no significant impact on the phosphorolysis kinetics with $\mathbf{1 a}$ as $k_{o b s}$ and all fit parameters remained largely unchanged across the working space (Figure 2A). Despite its deprotonation in the upper portion of the working space, a similar situation existed for 1b, albeit with a much lower and error-prone $\Delta S^{\ddagger}$ (Figure 2B). Although deprotonation severely affected GtPyNP's affinity for this substrate $\left(K_{\mathrm{M}}>10 \mathrm{mM}\right.$ at $\mathrm{pH} 9$ compared to $3.1 \mathrm{mM}$ at $\mathrm{pH} 7$, Figure S3D), it had no significant effect on the thermodynamic activation parameters, suggesting that transition state formation and binding are unaffected by the net charge of this substrate. Most likely, deprotonation of the substrate occurs per se in the active site of the enzyme where an anionic species would be well stabilized by positively charged residues (Scheme S1 and e.g. pdb ID 1 uou or $2 \mathrm{wk} 6$ ). As such, considering this mode of substrate complexation in pyrimidine NP active sites, it is reasonable to assume that even a partial dianion present during such a transformation can be accommodated (Scheme S1). Overall, the results of these experiments indicate that GtPyNPcatalyzed phosphorolysis is strikingly robust and shows little sensitivity to $\mathrm{pH}$ shifts or the protonation state of its nucleoside substrate, despite charge delocalization being a primary mechanism of rate acceleration in pyrimidine NPs. ${ }^{[48]}$ The fact that we obtained very similar Eyring plots over a broad $\mathrm{pH}$ range further indicates that the surface charge of the protein insignificantly contributed to the molecular dynamics and, in extension, activation heat capacity changes along the reaction coordinate. Nonetheless, it remains to be demonstrated if this behavior observed for the dimeric GtPyNP with a solvent-shielded active site also translates to highly multimeric enzymes or those with solvent-exposed active sites.

In conclusion, our kinetic characterization of GtPyNP revealed the presence of a measurable activation heat capacity change $\Delta C_{p}^{\ddagger}$, which showed no significant dependence on medium $\mathrm{pH}$ or substrate charge. Experiments across a wide working space uncovered the remarkable effects of a single halide substitution which has a minor influence on $\Delta C_{p}^{\ddagger}$ but conveys a significant kinetic effect by lowering the activation enthalpy, causing a $>10$ fold rate increase. Therefore, our results present an important piece in the understanding of enzymatic systems across multidimensional working spaces where the choice of reaction conditions can affect rate, affinity and thermodynamic phenomena independently of one another.
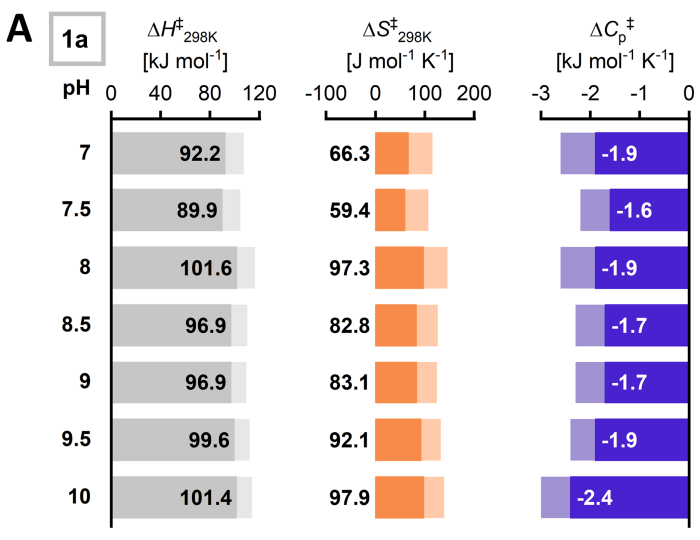

B
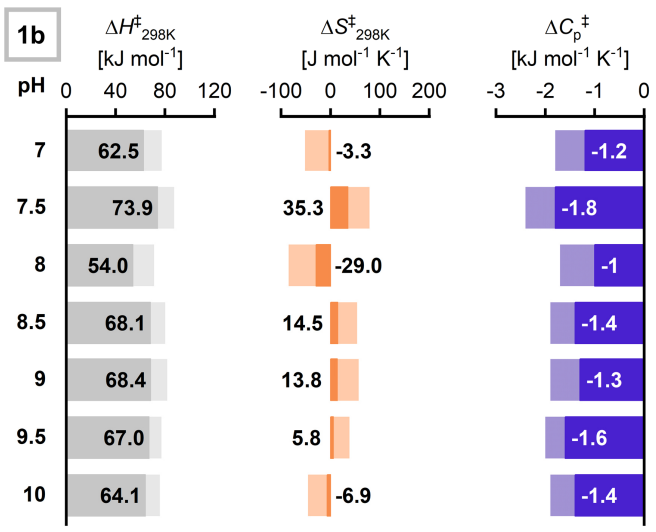

Figure 2. Activation thermodynamics of the GtPyNPcatalyzed phosphorolysis of $\mathbf{1 a}(\mathbf{A})$ and $\mathbf{1 b}(\mathbf{B})$ across the accessible working space. For clarity, errors (shaded bars) are only shown in one direction. Please see Table S3 for tabulated data as well as the externally hosted Supporting Information for raw data and calculations. ${ }^{[44]}$

\section{Acknowledgements}

The authors thank Kerstin Heinecke (TU Berlin) for proofreading and critical comments.

\section{Conflict of Interest}

A. K. is CEO of the biotech company BioNukleo $\mathrm{GmbH}$. F. K. is a scientist at BioNukleo GmbH and P. N. is a member of the advisory board. These affiliations constitute no conflict of interest with the results presented and discussed in this report.

\section{Author Information}

\section{Corresponding Author}

Felix Kaspar, felix.kaspar@web.de, orcid.org/0000-0001-6391-043X

\section{Other Authors}

Darian S. Wolff, orcid.org/0000-0002-9266-3017

Dr. Peter Neubauer, orcid.org/0000-0002-1214-9713

Dr. Anke Kurreck, orcid.org/0000-0001-6919-725X

Dr. Vickery L. Arcus, orcid.org/0000-0001-5082-2414 


\section{References}

[1] H. Eyring, J. Chem. Phys. 1935, 3, 107-115.

[2] P. W. Atkins, J. De Paula, Physical Chemistry, Oxford University Press, Oxford, 2010.

[3] V. L. Arcus, A. J. Mulholland, Annu. Rev. Biophys. 2020, 49, 163-180.

[4] V. L. Arcus, M. W. van der Kamp, C. R. Pudney, A. J. Mulholland, Curr. Opin. Struct. Biol. 2020, 65, 96101.

[5] V. L. Arcus, E. J. Prentice, J. K. Hobbs, A. J. Mulholland, M. W. Van der Kamp, C. R. Pudney, E. J. Parker, L. A. Schipper, Biochemistry 2016, 55, 16811688.

[6] J. K. Hobbs, W. Jiao, A. D. Easter, E. J. Parker, L. A. Schipper, V. L. Arcus, ACS Chem. Biol. 2013, 8, 23882393.

[7] M. W. van der Kamp, E. J. Prentice, K. L. Kraakman, M. Connolly, A. J. Mulholland, V. L. Arcus, Nat. Commun. 2018, 9, 1177.

[8] H. B. L. Jones, S. A. Wells, E. J. Prentice, A. Kwok, L. L. Liang, V. L. Arcus, C. R. Pudney, FEBS J. 2017, 284, 2829-2842.

[9] V. L. Arcus, C. R. Pudney, FEBS Lett. 2015, 589, 2200-2206.

[10] R. S. Firestone, S. A. Cameron, J. M. Karp, V. L. Arcus, V. L. Schramm, ACS Chem. Biol. 2017, 12, 464-473.

[11] H. B. L. Jones, R. M. Crean, C. Matthews, A. B. Troya, M. J. Danson, S. D. Bull, V. L. Arcus, M. W. van der Kamp, C. R. Pudney, ACS Catal. 2018, 8, 5340-5349.

[12] H. A. Bunzel, H. Kries, L. Marchetti, C. Zeymer, P. R. E. Mittl, A. J. Mulholland, D. Hilvert, J. Am. Chem. Soc. 2019, 141, 11745-11748.

[13] J. Åqvist, G. V. Isaksen, B. O. Brandsdal, Nat. Rev. Chem. 2017, 1, 51.

[14] V. Nguyen, C. Wilson, M. Hoemberger, J. B. Stiller, R. V Agafonov, S. Kutter, J. English, D. L. Theobald, D. Kern, Science 2017, 355, 289 LP - 294.

[15] S. Kamel, I. Thiele, P. Neubauer, A. Wagner, Biochim. Biophys. Acta - Proteins Proteomics 2020, 1868, 140304.

[16] M. J. Pugmire, S. E. Ealick, Biochem. J. 2002, 361, 125.

[17] A. Bronckaers, F. Gago, J. Balzarini, S. Liekens, Med. Res. Rev. 2009, 29, 903-953.

[18] M. J. Pérez-Pérez, E. M. Priego, A. I. Hernández, M. J. Camarasa, J. Balzarini, S. Liekens, Mini Rev. Med. Chem. 2005, 5, 1113.

[19] W. Li, H. Yue, Trends Cardiovasc. Med. 2018, 28, 157-171.

[20] R. G. Silva, J. E. Nunes, F. Canduri, J. C. Borges, L. M. Gava, F. B. Moreno, L. A. Basso, D. S. Santos, Curr. Drug Targets 2007, 8, 413.

[21] J. M. Dziekan, H. Yu, D. Chen, L. Dai, G. Wirjanata, A. Larsson, N. Prabhu, R. M. Sobota, Z. Bozdech, P. Nordlund, Sci. Transl. Med. 2019, 11, eaau3174.

[22] L. H. Pogosian, L. S. Nersesova, M. G. Gazariants, Z. S. Mkrtchian, J. I. Akopian, Biochem. Suppl. Ser. B Biomed. Chem. 2011, 5, 60.
[23] S. Kamel, H. Yehia, P. Neubauer, A. Wagner, in Enzym. Chem. Synth. Nucleic Acid Deriv. (Ed.: F. J.), 2018, 1-28.

[24] S. Kamel, M. Weiß, H. F. T. Klare, I. A. Mikhailopulo, P. Neubauer, A. Wagner, Mol. Catal. 2018, 458, 52-59.

[25] F. Kaspar, M. R. L. Stone, P. Neubauer, A. Kurreck, Green Chem. 2020, DOI 10.1039/D0GC02665D.

[26] F. Kaspar, R. T. Giessmann, K. F. Hellendahl, P. Neubauer, A. Wagner, M. Gimpel, ChemBioChem 2020, 21, 1428-1432.

[27] I. V Kulikova, M. S. Drenichev, P. N. Solyev, C. S. Alexeev, S. N. Mikhailov, European J. Org. Chem. 2019, 2019, 6999-7004.

[28] M. S. Drenichev, C. S. Alexeev, N. N. Kurochkin, S. N. Mikhailov, Adv. Synth. Catal. 2018, 360, 305-312.

[29] F. Kaspar, P. Neubauer, A. Kurreck, ChemPhysChem 2020, $n / a$, DOI 10.1002/cphc.202000901.

[30] K. F. Jensen, P. Nygaard, Eur. J. Biochem. 1975, 51, 253-265.

[31] M. Ghanem, L. Li, C. Wing, V. L. Schramm, Biochemistry 2008, 47, 2559-2564.

[32] M. D. Erion, J. D. Stoeckler, W. C. Guida, R. L. Walter, Biochemistry 1997, 36, 11735-11748.

[33] A. Bzowska, E. Kulikowska, D. Shugar, Zeitschrift für Naturforsch. C 1993, 48, 803-811.

[34] X. Xie, W. Huo, J. Xia, Q. Xu, N. Chen, Enzyme Microb. Technol. 2012, 51, 59-65.

[35] G. Mikleušević, Z. Štefanić, M. Narczyk, B. WielgusKutrowska, A. Bzowska, M. Luić, Biochimie 2011, 93, 1610-1622.

[36] D. J. Porter, J. Biol. Chem. 1992, 267, 7342-7351.

[37] G. V. Isaksen, J. Åqvist, B. O. Brandsdal, Biochemistry 2017, 56, 306-312.

[38] F. Kaspar, P. Neubauer, A. Kurreck, ChemBioChem 2020, $n / a$, DOI 10.1002/cbic.202000679.

[39] F. Kaspar, R. T. Giessmann, P. Neubauer, A. Wagner, M. Gimpel, Adv. Synth. Catal. 2020, 362, 867-876.

[40] R. T. Giessmann, F. Kaspar, P. Neubauer, in preparation, preliminary dataset available at https://doi.org/10.5281/zenodo.3572070.

[41] Y. H. Jang, L. C. Sowers, T. Çağin, W. A. Goddard, J. Phys. Chem. A 2001, 105, 274-280.

[42] F. Kaspar, R. T. Giessmann, S. Westarp, K. F. Hellendahl, N. Krausch, I. Thiele, M. C. Walczak, P. Neubauer, A. Wagner, ChemBioChem 2020, 21, 2604.

[43] F. Kaspar, R. T. Giessmann, N. Krausch, P. Neubauer, A. Wagner, M. Gimpel, Methods Protoc. 2019, 2, 60.

[44] F. Kaspar, 2020, DOI 10.5281/zenodo.4534199.

[45] H. Akaike, in 2nd Int. Symp. Inf. Theory, Tsahkadsor, Armen. USSR (Eds.: B.N. Petrov, F. Csáki), 1973, 267281.

[46] K. Szeker, X. Zhou, T. Schwab, A. Casanueva, D. Cowan, I. A. Mikhailopulo, P. Neubauer, J. Mol. Catal. B Enzym. 2012, 84, 27-34.

[47] D. S. Tawfik, Curr. Opin. Chem. Biol. 2014, 21, 73 80.

[48] P. N. Edwards, J. Enzyme Inhib. Med. Chem. 2006, 21, 483-518. 